\title{
Collaboration between the national institute of nuclear research and the national institute of rehabilitation "dr. luis guilermo ibarra ibarra", mexico
}

\section{Introduction}

In Mexico, loss of skin due to burns is a very important public health problem. Burns can cause serious incapacities: physical, psychological, social and labor, with high mortality index and severe sequels due to scars. Autologous skin transplant is the best option for patients suffering burns, ulcers, dystrophic epidermolysis bullosa among others, but for those patients with high percentage of total body surface area (TBSA) burned, is almost impossible to find healthy skin sites for tissue transplant. The second option is the use of banked skin of cadaveric donors, but in Mexico, the rate of organ and tissue donation still is too low, $4.06 \times 106$ inhabitants, ${ }^{1}$ so is quite difficult to have skin available in the few skin banks of the country. Diabetic ulcers are also a very important health problems, so is imperative to develop alternative treatments for damaged skin restoration. Tissue engineering is considering as a promising field for the development of tissue substitutes, based on the use of biomaterials and cells to create organ and tissue substitutes.

\section{ININ: radiosterilized tissue bank activities}

The Banco de Tejidos Radioesterilizados (BTR, Radiosterilized Tissue Bank), is a non-profit tissue bank, which belongs to the Instituto Nacional de Investigaciones Nucleares (ININ, National Institute of Nuclear Research). This bank was established thanks to the great support of the International Atomic Energy Agency (IAEA) given to ININ through a national project, executed in 1997-1998. The BTRININ has its Sanitary License, issued on July 6, 1999 by the Health Secretariat (SSA), being the first tissue bank in the country that uses Co-60 gamma radiation as sterilizing agent. ${ }^{2}$ Later on, more banks were established in different cities, ${ }^{3}$ some of them also use ionizing radiation to sterilize their tissues and conditioning materials at the ININ JS 6500 AECL Cobalt-60 industrial irradiator. The BTR-ININ is located in the federal highway Mexico-Toluca, at West of Mexico City.

The BTR-ININ has implemented the process for amniotic membrane, human skin, pig skin and muscle-skeletal tissues. On May 2nd, 2017, the ININ signed an agreement with the Instituto Materno Infantil del Estado de México, its Hospital de Ginecología y Obstetricia and the Centro Estatal de Trasplantes del Estado de México, to assure amnion supply. Since 2001, the pig skin is kindly donated to the BTR-ININ by the company "Abastos Cautitlán, S.A. de C.V.", which is a private federal inspection type slaughterhouse at North of Mexico City in Mexico State.

The BTR-ININ facilities have the minimum area and equipment for animal and human tissues processing, such as laminar flow cabinets (3, one for amnion and human skin, one for muscle-skeletal tissues and the third is exclusive for pig skin), deep-freezers $\left(-80^{\circ} \mathrm{C}\right.$, $-40^{\circ} \mathrm{C}$ and $\left.-20^{\circ} \mathrm{C}\right)$, freeze-dryings $(2$, one for animal tissue and one for human tissues), steam sterilizer, materials conditioning area, final product storage, retention samples museum, Quality Management System (QMS) documentation storage area -standard operating

\author{
Volume 2 Issue 6 - 2017
}

\begin{abstract}
María Esther Martínez Pardo,' Roberto Sánchez Sánchez, ${ }^{2}$ Cristina Velasquillo²

'Banco de Tejidos Radioesterilizados, Instituto Nacional de Investigaciones Nucleares (ININ), Mexico

${ }^{2}$ Laboratorio de Biotecnología, Instituto Nacional de

Rehabilitación “Dr. Luis Guilermo Ibarra Ibarra” (INR), Mexico

Correspondence: María Esther Martínez Pardo, Banco de Tejidos Radioesterilizados, Instituto Nacional de Investigaciones Nucleares (ININ), Carretera México-Toluca S/N, La Marquesa, 52750 Ocoyoacac, Edo. de México, México, Tel +52 555329 7108,Email esther.martinez@inin.gob.mx
\end{abstract}

Received: July 12, 2017 | Published: September 15, 2017

procedures, instructions, registers, mappings and the like-, etc. The bank has also the support of the following ININ laboratories: Laboratory of Microbiology for microbiological control of tissues and facilities; ${ }^{4}$ Laboratory of Chemical Analysis for tissue humidity content and Radioactive Materials Department for final sterility test of all irradiated tissues.

The QMS of the BTR-ININ has the ISO 900:2008 certification since August 1, 2003. ${ }^{5}$ This tissue bank currently processes airdried human amnion; porcine skin, frozen and lyophilized, as well as muscle-skeletal tissues. These tissues are radiation sterilized at a minimum dose of $25 \mathrm{kGy}$, at the ININ JS 6500 irradiator, to achieve a $1 \times 10^{-6}$ Sterility Assurance Level. Since 2001, the BTR has been distributing its radiation sterilized tissues to public as well as some private hospitals in many cities, that take care of needed people. Amnion and porcine skin are biological wound dressings used for treatment of full and partial thickness burns, among other clinical applications. ${ }^{6,7}$ In 2004, the irradiated amnion started to be used for ophthalmologic applications at the public Hospital General de México Dr. Eduardo Liceaga (HGM). ${ }^{8}$ Bone and muscle-skeletal tissues processed and radiation sterilized at the BTR have great demand, especially at Shriners Hospital for Children and at the Instituto Nacional de Pediatría, both for paediatric patients in Mexico City.

\section{INR: laboratory of biotechnology activities}

The National Centre for Research and Attention of Burned Patients (CENIAQ), which belongs to the Instituto Nacional de Rehabilitación "Dr. Luis Guillermo Ibarra Ibarra" (INR, National Institute of Rehabilitation), is a specialized center for the attention of burned patients from the whole country. This centre has the ISO 9001:2008 and NMX-CC-9001-IMNC-2008 certifications. The Laboratory of Biotechnology (LB-INR), which is part of CENIAQ, is a well-recognized service unit and part of its functions are: 
A. To develop biological substitutes, by using tissue engineering and regenerative medicine for the attention of the hospital's patients;

B. To generate research about the cellular mechanisms to form skin, cartilage, bone;

C. To understand the mesenchymal stem cells properties and its potential applications in regenerative medicine; and

D. To develop biomaterials that can be used as scaffolds for cell transplant. To conduct these functions, the LB-INR offers advice and collaboration by research agreements with others laboratories and institutions.

The LB-INR has the infrastructure for cell culture for the treatment of different diseases according to the specialization of the mentioned institution. The LB-INR is a class 100 laboratory with Good Manufacturing Practice implemented, areas with deep freezers $\left(-20^{\circ} \mathrm{C},-80^{\circ} \mathrm{C}\right)$, flow cytometry FACS Aria III and Confocal Microscopy, frozen cells preservation, materials conditioning, etc. Among the specialized equipment, there are inverted, vertical and epiinmunofluorescence incubation microscopes. The research lines in force of the LB-INR are the following: Development and application of skin biological substitutes for burns, development and application of cartilage biological substitutes to repair auricular cartilage wounds, development and application of outer ear or pinna biological substitutes for patients with microtia (underdeveloped outer ear), among others. ${ }^{9}$

\section{BTR-LB collaboration}

Based on previous collaboration with the HGM, the BTR-ININ and the LB-INR started a joint research, to determine if the amnion sterilized with gamma radiation could be used as a matrix for limbal stem cells culture. ${ }^{10}$ The promising results originated that in 2014, trying to overcome the need of skin, the two last institutions decided to work under the framework of an IAEA Coordinated Research Project, CRP E.3.10.07 "Instructive Surfaces and Scaffolds for Tissue Engineering using Radiation Technology", actually in force together with 14 countries.

The main goal of this current joint research is to develop biological skin substitutes based on radiation sterilized human amnion (RHA) and radiation sterilized porcine skin (RPS), processed and sterilized at the BTR. Currently skin substitutes, based on RPS seeded with autologous human cells, are developing in the LB and they will be used for the treatment of partial burned patients at CENIAQ. The development of those biomaterials will allow us to use bioengineering technology for the treatment of burned people, not only at CENIAQ but also in other public hospitals in the country. The experimental work on cell culture to develop biological skin substitutes -IAEA research contract-, based on an animal model, is carried out at the LB-INR facility. ${ }^{11}$ The group of researchers is currently working in clinical trials to test if RHA and RPS are suitable scaffolds for the culture of fibroblast, keratinocytes and mesenchymal stem cells for the treatment of burns.

\section{Conclusion}

The results obtained at this stage are very promising, because the RHA and RPS are good scaffolds for cell culture. The collaboration between institutions let the research progress in a faster way, here is the importance of develop multidisciplinary work groups in benefit of patients that need the advance of science to heal their diseases.

\section{Conflict of interest}

The author declares no conflict of interest.

\section{Acknowledgements}

The authors express their thankfulness to the International Atomic Energy Agency for the support to the BTR-ININ (different kind of projects executed since 1997), as well as the financial support to ININ and INR through the Research Contract 18278.

\section{References}

1. Página del Centro Nacional de Trasplantes; 2016.

2. Jorge Morales Pedraza. Ethical policy and principles in tissue banking, Switzerland: Springer International Publishing; 2016. p. 119-121.

3. Esther Martínez Pardo M, Lourdes Reyes Frías M. The tissue bank at the national nuclear research institute in Mexico. Cell Tissue Bank. 2003;4(2-4):163-168.

4. Eulogia Kairiyama, Celina Horak, Isabel Otero, et al. Emma Castro y María del Carmen Saldías Código de Prácticas para la Esterilización por Irradiación de tejidos Humanos para Uso Clínico: Requisitos para la Validación y Control de Rutina. OIEA, Editorial Tecnológica de Costa Rica, International Atomic Energy Agency, Noviembre; 2013.

5. Martínez Pardo ME, Mariano Magaña D. The tissue bank at the instituto nacional de investigaciones nucleares: ISO 9001:2000 certification of its quality management system. Cell Tissue Bank. 2007;8(3):221-231.

6. Martínez Pardo ME, Ley Chávez E, Reyes Frías ML, et al. Biological wound dressings sterilised with gamma radiation: mexican clinical experience. Radiat Phys Chem. 2007;76(11-12):1771-1774.

7. Ma de Lourdes Reyes Frías, María Esther Martínez Pardo, Daniel Luna Zaragoza, et al. Avances del Banco de Tejidos Radioesterilizados del Instituto Nacional de Investigaciones Nucleares. 2010;3:37-51.

8. Leticia Vázquez Maya, Marco Antonio Salazar Escamilla, et al. Use of amniotic membrana radiosterilized with cobalt-60 for reconstruction of ocular surface. Rev Med Hosp Gen Mex. 2009;72(1):7-15.

9. Página del Instituto Nacional de Rehabilitación; 2017.

10. Landa Solís C, Vázquez Maya L, Martínez Pardo ME, et al. Use of irradiated human amnion as a matrix for limbal stem cell culture. Cell Tissue Bank. 2013;14(1):78-84.

11. Sánchez Sánchez R, Brena Molina A, Martínez López V, et al. Generation of two biological wound dressings as a potential delivery system of human adipose-derived mesenchymal stem cells. ASAIO J. 2015;61(6):718-725. 